\title{
Mechanical Comparison of a Novel Hybrid and Commercial Dorsal Double Plating for Distal Radius Fracture: In Vitro Fatigue Four-Point Bending and Biomechanical Testing
}

\author{
Hsuan-Chih Liu ${ }^{1,2}$, Yu-Hui Zeng ${ }^{2}$ and Chun-Li Lin ${ }^{2, *(1)}$ \\ 1 Division of Orthopedics, Chi Mei Hospital, Liouying, Tainan City 710, Taiwan; mvphoton@gmail.com \\ 2 Department of Biomedical Engineering, National Yang Ming Chiao Tung University, Taipei 112, Taiwan; \\ yuhui8762@gmail.com \\ * Correspondence: cllin2@nycu.edu.tw
}

\section{check for}

updates

Citation: Liu, H.-C.; Zeng, Y.-H.; Lin, C.-L. Mechanical Comparison of a Novel Hybrid and Commercial Dorsal Double Plating for Distal Radius Fracture: In Vitro Fatigue Four-Point Bending and Biomechanical Testing. Materials 2021, 14, 6189. https://doi.org/10.3390/ ma14206189

Academic Editors: Reza Hashemi and Antonio Scarano

Received: 13 July 2021

Accepted: 11 October 2021

Published: 18 October 2021

Publisher's Note: MDPI stays neutral with regard to jurisdictional claims in published maps and institutional affiliations.

Copyright: (c) 2021 by the authors. Licensee MDPI, Basel, Switzerland. This article is an open access article distributed under the terms and conditions of the Creative Commons Attribution (CC BY) license (https:// creativecommons.org/licenses/by/ $4.0 /)$.
Abstract: This study compares the absolute and relative stabilities of a novel hybrid dorsal double plating (HDDP) to the often-used dorsal double plating (DDP) under distal radius fracture. The " $Y$ " shape profile with $1.6 \mathrm{~mm}$ HDDP thickness was obtained by combining weighted topology optimization and finite element (FE) analysis and fabricated using Ti6Al4V alloy to perform the experimental tests. Static and fatigue four-point bending testing for HDDP and straight L-plate DDP was carried out to obtain the corresponding proof load, strength, and stiffness and the endurance limit (passed at $1 \times 10^{6}$ load cycles) based on the ASTM F382 testing protocol. Biomechanical fatigue tests were performed for HDDP and commercial DDP systems fixed on the composite Sawbone under physiological loads with axial loading, bending, and torsion to understand the relative stability in a standardized AO OTA 2R3A3.1 fracture model. The static four-point bending results showed that the corresponding average proof load values for HDDP and DDPs were $109.22 \mathrm{~N}$ and $47.36 \mathrm{~N}$, that the bending strengths were $1911.29 \mathrm{~N} / \mathrm{mm}$ and $1183.93 \mathrm{~N} / \mathrm{mm}$, and that the bending stiffnesses were $42.85 \mathrm{~N} / \mathrm{mm}$ and $4.85 \mathrm{~N} / \mathrm{mm}$, respectively. The proof load, bending strength and bending stiffness of the HDDPs were all significantly higher than those of DDPs. The HDDP failure patterns were found around the fourth locking screw hole from the proximal site, while slight plate bending deformations without breaks were found for DDP. The endurance limit was $76.50 \mathrm{~N}$ (equal to torque $1338.75 \mathrm{~N} / \mathrm{mm}$ ) for HDDP and $37.89 \mathrm{~N}$ (equal to torque $947.20 \mathrm{~N} / \mathrm{mm}$ ) for DDP. The biomechanical fatigue test indicated that displacements under axial load, bending, and torsion showed no significant differences between the HDDP and DDP groups. This study concluded that the mechanical strength and endurance limit of the HDDP was superior to a commercial DDP straight plate in the four-point bending test. The stabilities on the artificial radius fractured system were equivalent for novel HDDP and commercial DDP under physiological loads in biomechanical fatigue tests.

Keywords: distal radius fracture; dorsal plate; biomechanical test; four-point bending test

\section{Introduction}

Distal radius fractures are the most common injuries encountered in orthopedics, which represent $17.5 \%$ of all fractures [1]. There are several options for the operative treatment of unstable fractures. Open reduction and plate fixation are the most common treatments for this type of injury. The surgical approach and plate selection should correlate with the fracture configuration. Although volar plating is more widely used, dorsal plating may be more reliably in preventing re-displacement in some instances of dorsally displaced metaphyseal fragments than volar plating.

Conventional dorsal plate application could result in wrist extensor tendon irritation and occasional extensor tendon rupture. The use of modern dorsal locking plates improved the clinical results and reduced the number of complications [2]. The three column concept 
introduced by Rikli and Regazzoni divides the distal radius and ulna into radial, intermediate, and ulnar columns [3]. Following the three column theory principles, by applying more than one low profile plate in the orthogonal plane with an angle of $50-70^{\circ}$, a multi-planar, load-sharing construct anatomically restores the articular surface while providing enough stability to allow immediate motion after surgery. AO/ASIF (Synthes, Paoli, PA, USA) 2.4-mm low-profile locking fragment-specific implants were then developed and are now widely used.

Although dorsal double-plating (DDP) has shown promising results, it still has some unsolved problems, including increased surgical time and cost. In addition, the fixation screws in the dorsal-volar direction of the T plate might interfere with the screw in the straight I plate radial-ulnar direction because of the limited distal fragment space [4]. Inadequate subchondral support due to fewer distal screw numbers is still a concern. An ideal fixation for the distal radius does not exist and optimal treatment remains a therapeutic challenge. To overcome these problems, a new dorsal locking plate, hybrid dorsal double plate (HDDP), has been designed based on weighted topology optimization and finite element analysis [5]. The HDDP is a "Y"-shaped plate with two ears on the top of the dorsal-radial and -ulnar sides to provide adequate support to the distal fragment. Multiple screws are inserted at the top dorsal-radial/-ulnar ears of the HDDP to enhance the stability. Early numerical biomechanical evaluation reported promising results. From the FE analysis [5], the stress concertation was noted in the DDP group. The DDP intermediate and styloid plate stress concentrations were found at the middle of the plates (around the fracture sites). This might increase the risk for implant failure. On the other hand, stress concentration was not significant in the HDDP group. By changing the shape of the plate, the stress on the plate can be redistributed, so the risk for stress concertation could be diminished. However, clinical data are still awaited.

This study aimed to compare the absolute and relative stability of the newly designed HDDP with the often-used DDP under in vitro fatigue four-point bending and biomechanical tests in an anatomically fashioned synthetic bone model. The hypothesis of this article is that the novel plate shows equivalent or superior mechanical properties in load-bearing capacity and endurance.

\section{Materials and Methods}

\subsection{HDDP Design and Manufacture}

The novel HDDP profile presents a "Y" shape with $1.6 \mathrm{~mm}$ thickness, obtained by combining weighted topology optimization and finite element $(\mathrm{FE})$ analysis under six fracture models with $50 \%, 30 \%$, and $20 \%$ weights of the joint subjected to axial, bending, and torsion moments, respectively, as presented in our previous study [5] (Figure 1a). The novel HDDP has been approved with the best optimal structural strength when compared with the DDP approach and the novel HDDP achieves the objective of being light weight with a single-wound surgical approach. The two ears' geometric features on the distal top of the dorsal-radial and -ulnar sides with eight locking screws and no screw interferences were designed to provide adequate support to distal articular comminuted fractures. The HDDP can be placed on the dorsal site of the distal radius through the standard dorsal approach. The numerical biomechanical simulation results indicated that the novel HDDP demonstrated better resistances to functional loads and provided sufficient screw fixation at the articular surface than those with DDP (Figure 1c), regardless of the bone fracture type.

The physical model of novel HDDP is composed of Ti6Al4V alloy (Figure 1a) and fabricated using an ISO13485 quality management systems company (Microware Precision Technology Co., Ltd., Taichung City, Taiwan) for the following fatigue four-point bending and biomechanical tests. 


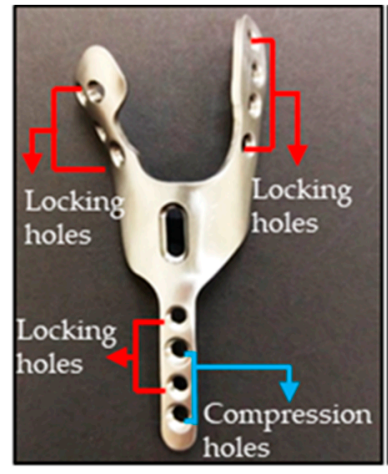

(a)

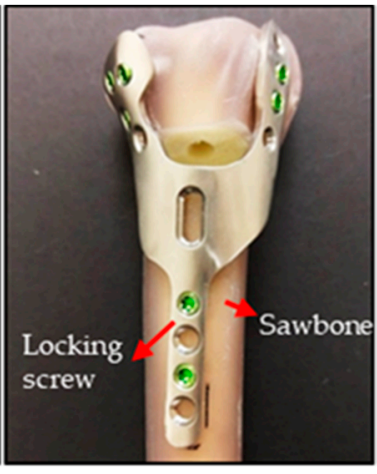

(b)

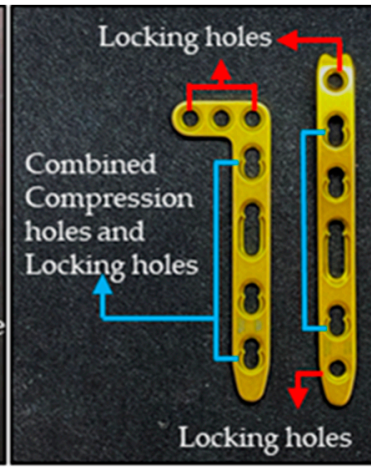

(c)

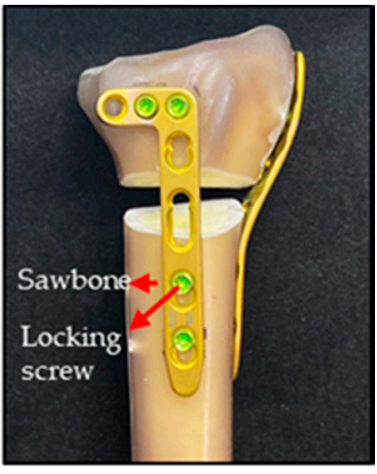

(d)

Figure 1. (a) Profile of the novel HDDP presented a "Y" shape with $1.6 \mathrm{~mm}$ thickness, fabricated using Ti6Al4V alloy. (b) The HDDP was fixed onto one of the radius Sawbones using self-tapping $2.4 \mathrm{~mm}$ locking screws bicortically in the shaft and unicortically in the distal end. (c) The dorsal double-plating (DDP) consists of one "L" shape plate and one straight plate with $1.6 \mathrm{~mm}$ thickness, fabricated using Ti6CP alloy. (d) The DDP was fixed onto one of the radius Sawbones using self-tapping $2.4 \mathrm{~mm}$ locking screws bicortically in the shaft and unicortically in the distal end around the fixation screws.

\subsection{Four-Point Bending Mechanical Testing}

To provide a comprehensive mechanical strength reference for bone plates used in the surgical internal fixation of the skeletal system, four-point bending tests were carried out for novel HDDP and commercial bone plate according to the American Society for Testing and Materials (ASTM) protocols (ASTM F382-17), using the Instron E10000 testing machine (INSTRON, Canton, MA, USA). The commercial straight L-plate titanium locking compression double plate fragment-specific system (LCP L/I 2.4, Deupy Synthes, Synthes $\mathrm{GmbH}$, Eimattstrasse, Switzerland) was set as the comparison group with HDDP in the static and fatigue tests.

Static testing was performed first to obtain the proof load, strength, and stiffness of the samples. The rigid extension segments used to effectively lengthen the bone plate due to the HDDP do not have a symmetrical section, and the L-plate does not have a sufficiently long symmetrical section. The geometry profile at the proximal and distal sides of the rigid extension segments for the HDDP were designed according to their corresponding geometric features of the contact bone plate and fabricated using a metal 3D printer (AM 400, Renishaw, Gloucestershire, UK). The HDDP and L-plate were fixed onto the corresponding rigid extension segments and the loading rollers contact the rigid extension segments of the test setup during the test (Figure 2).

Center span (a) is the distance between the loading rollers and $70 \mathrm{~mm}$ for the HDDP and $50 \mathrm{~mm}$ for the L-plate test samples. Additionally, the loading span distance (h) is the distance between the loading roller and nearest support roller. The corresponding distances for the HDDP and L-plate samples were $35 \mathrm{~mm}$ and $50 \mathrm{~mm}$, respectively (Figure 2). Each group had three samples and were placed on the four-point bending test clamp to load at a cross-head rate of $0.05 \mathrm{~mm} / \mathrm{s}$ until failure occurred. The proof load (P), plate deflection, and force-displacement diagram were collected from each test, and the corresponding bending strength, bending stiffness $(\mathrm{K})$, and bending structural stiffness were calculated. The failure pattern of each sample was visually examined to assess the failure mechanism.

According to the ASTM F382 standard test method, bending stiffness (K) was determined by measuring the linear portion slope of the load-displacement curve. The bending structural stiffness (EI) was derived from the four-point bending load apparatus as follows:

$$
\text { Bending Structural Stiffness }=\mathrm{EI}=[(2 \mathrm{~h}+3 \mathrm{a}) \mathrm{kh} 2 / 12] \text {, }
$$

Bending strength was calculated using the following formula:

$$
\text { Bending Strength }=\mathrm{Ph} / 2 \text {, }
$$


where $\mathrm{P}$ is the proof load at the intersection line of a $0.2 \%$ offset from the linear portion of the load-displacement curve in the load versus load-displacement curve.
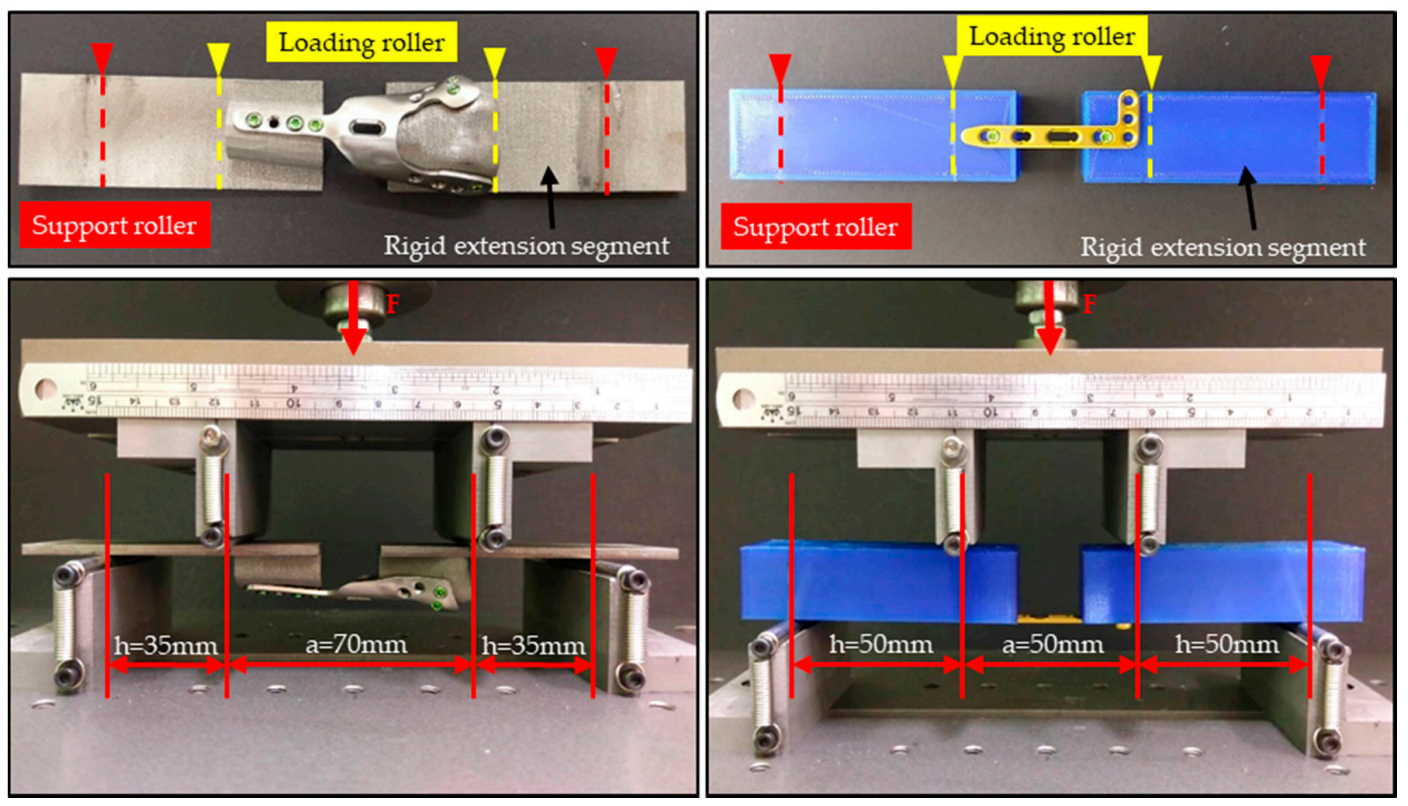

Figure 2. The HDDP (left part) and L-plate (right part) were fixed onto the corresponding rigid extension segments; the loading rollers made contact with the rigid extension segments of the test setup during the test.

The fatigue test was performed according to the result of the proof load obtained from the static four-point bending test. The fatigue tests were run using a sinusoidal cyclic load waveform at a constant frequency of $5 \mathrm{~Hz}$ in the four-point bending apparatus. Fatigue testing was considered complete when either the limit of one million cycles was reached or when failure occurred, either through cracking or plastic deformation, resulting in a displacement greater than twice the initial displacement. There were $90 \%, 80 \%$, and $70 \%$ of the proof load values tested in the HDDP group and $95 \%, 90 \%$ and $80 \%$ of the proof load values tested in the L-plate group. Three samples were investigated in each load condition.

\subsection{Biomechanical Fatigue Test}

In order to more closely simulate the bone plate load under physiological conditions, biomechanical fatigue tests were performed to compare the mechanical responses between the newly developed HDDP and commercial DDP systems using a composite Sawbone (Sawbones; Pacific Research Laboratories Inc., Vashon Island, WA, USA). Sawbone has been previously proven to have similar mechanical properties to cadaver bone [6]. As the synthetic bone is produced industrially, its availability, comparability, and reproducibility are superior to natural bone.

Eighteen Sawbone radii were prepared and cut at the proximal third of the bone, giving a length of $230 \mathrm{~mm}$ to allow for standardized embedding in an epoxy resin block. A standardized AO OTA 2R3A3.1 fracture model was created with a $10 \mathrm{~mm}$ dorsal defect, $20 \mathrm{~mm}$ distal to the articular surface to simulate the extra-articular fracture. Our novel HDDP and commercial DDP were fixed, respectively, onto nine of the Sawbones radii using self-tapping $2.4 \mathrm{~mm}$ locking screws bicortically in the shaft and unicortically in the distal end (Figure 1b,d).

The HDDP and DDP groups were divided into three subgroups, including axial load, bending, and torsion. All of the biomechanical fatigue tests were performed using the Instron 10,000 testing machine with 20,000 load cycles to represent the upper end of the estimated physiological loads seen over the usual 6-month healing time for this injury [7-11]. The specimens were subjected to all loads oscillated between $15 \mathrm{~N}$ and $150 \mathrm{~N}$ at $5 \mathrm{~Hz}$ for axial load, $5.5 \mathrm{~N}$ to a maximum of $55 \mathrm{~N}$ at $5 \mathrm{~Hz}$ for bending, and $-1 \mathrm{~N}-\mathrm{m}$ to $1 \mathrm{~N}-\mathrm{m}$ 
at $5 \mathrm{~Hz}$ for torsion. The maximum applied load represents the upper end of the estimated physiological forces with wrist motion $[7,10,12,13]$. Three kinds of loads were respectively applied to the distal radial surface through the corresponding specific loading devices (Figure 3). One-way analyses for axial displacement under axial load, lateral displacement under bending, and rotational degree under torsion between HDDP and DDP fixations were performed after the fatigue tests to understand the statistical significance.
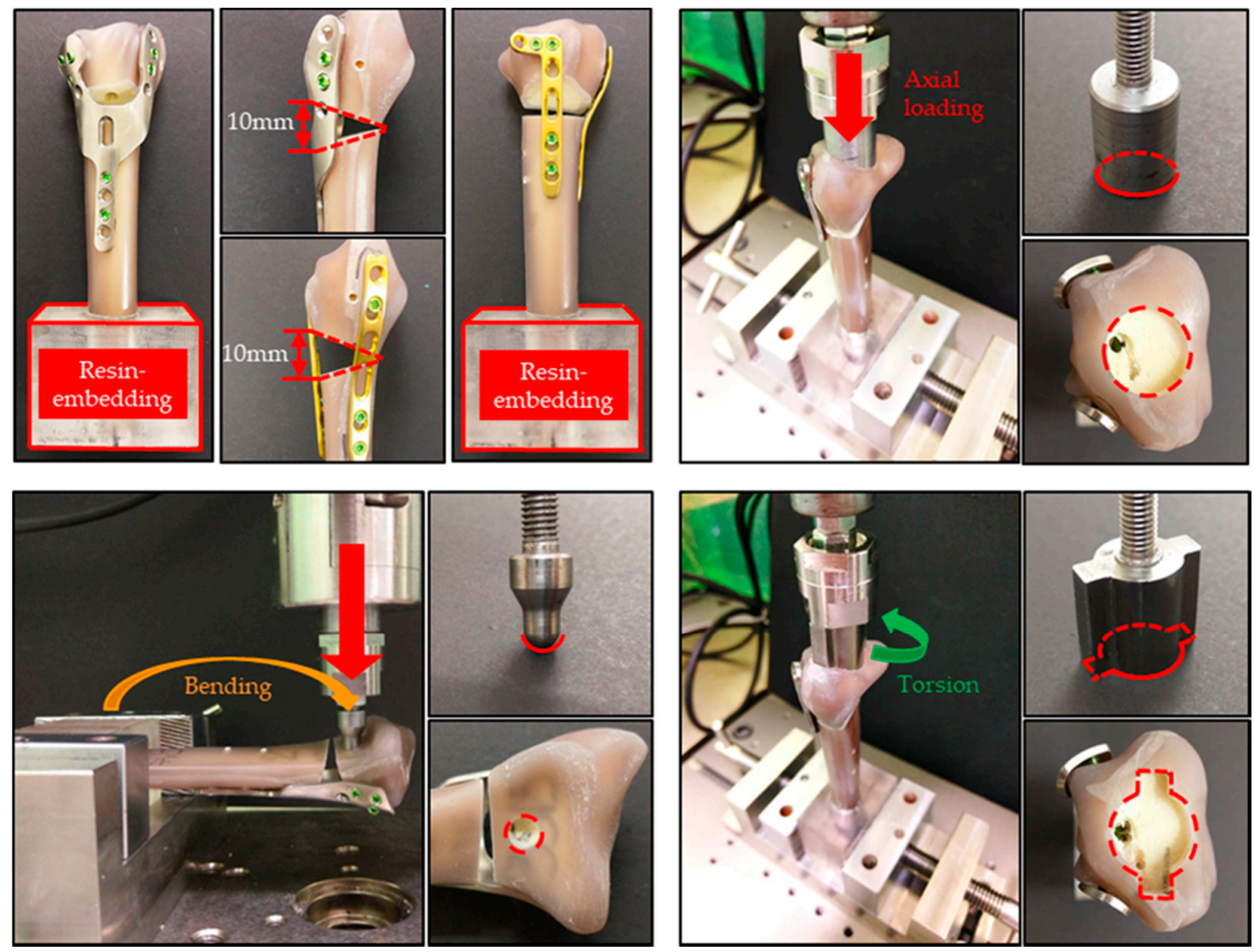

Figure 3. The HDDP and DDP were fixed onto the fractured Sawbone radius (upper-left part). The fractured Sawbone radius was embedded with resin for stable fixation on the vise. Three kinds of loads (axial load, bending, and torsion at the upper-right, lower-left, and lower-right parts, respectively) were applied to the distal radial surface through the corresponding specific loading devices.

\section{Results}

In the static four-point bending test, the corresponding values for HDDP and DDPs of the average proof load were $109.22 \pm 8.17 \mathrm{~N}$ and $47.36 \pm 5.36 \mathrm{~N}$ (Figure 4), the bending strengths were, $1911.29 \pm 142.93 \mathrm{~N} / \mathrm{mm}$ and $1183.93 \pm 134.09 \mathrm{~N} / \mathrm{mm}$, and the bending stiffnesses were, $42.85 \pm 9.21 \mathrm{~N} / \mathrm{mm}$ and $4.85 \pm 0.20 \mathrm{~N} / \mathrm{mm}$, respectively. The proof load, bending strength, and bending stiffness of the HDDPs were all significantly higher than those for DDPs.

In the fatigue four-point bending test, fatigue M-N diagrams of the HDDP and DDP groups are plotted in Figure 5. The HDDP past one million cycle load fatigue limit was $76.50 \mathrm{~N}$ (equal to torque $1338.75 \mathrm{~N} / \mathrm{mm}, 70 \%$ of the proof load) (Figure $5 \mathrm{a}$ ), and the corresponding DDP group value was $37.89 \mathrm{~N}$ (equal to torque $947.20 \mathrm{~N} / \mathrm{mm}, 80 \%$ proof load) (Figure $5 \mathrm{~b}$ ). All three samples failed in $90 \%$ of the proof load tests $(98.3 \mathrm{~N}$, equal to $1720.25 \mathrm{~N} / \mathrm{mm}$ ), two samples withstood one million cycles, and one sample failed in $80 \%$ of the proof load tests $(87.4 \mathrm{~N}$, equal to $1529.5 \mathrm{~N} / \mathrm{mm}$ ) for the HDDP group. In contrast with DDP, all three samples failed in $95 \%$ of the proof load tests $(45.00 \mathrm{~N}$, equal to $1125.00 \mathrm{~N} / \mathrm{mm}$ ), one sample withstood one million cycles and two samples failed in $90 \%$ of the proof load tests $(42.62 \mathrm{~N}$, equal to $1065.0 \mathrm{~N} / \mathrm{mm})$ of the DDP group (Table 1 ). 


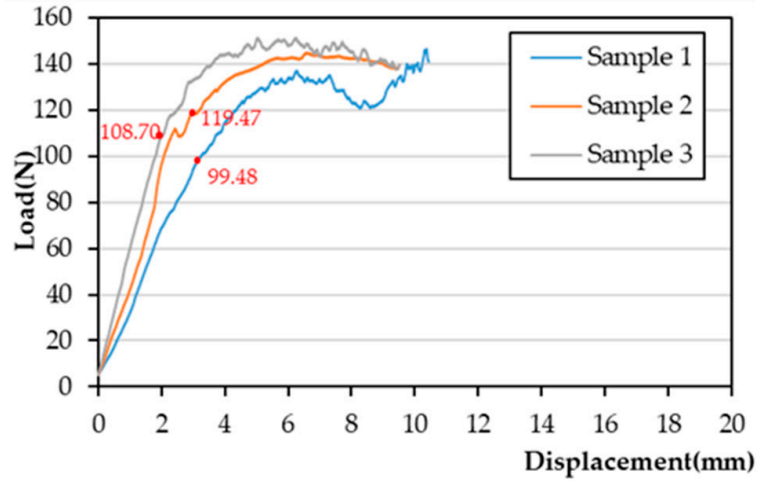

(a)

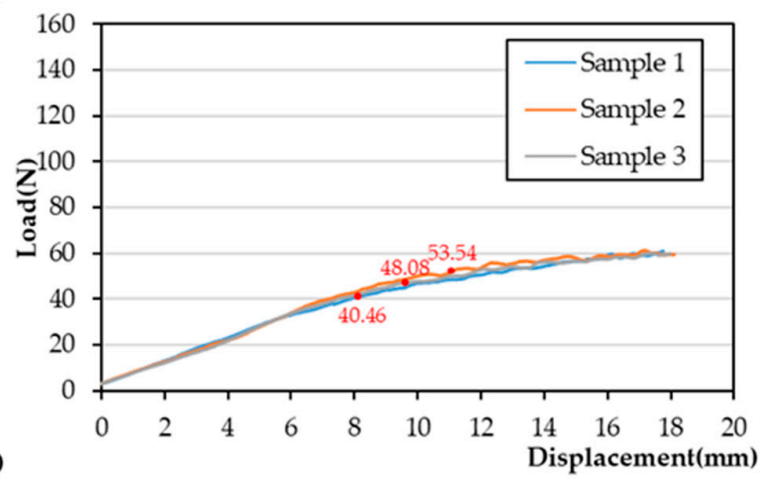

(b)

Figure 4. Static four-point bending test load displacement diagrams for HDDP and DDP. The red dots indicate the proof load (a) for HDDP and (b) for DDP.

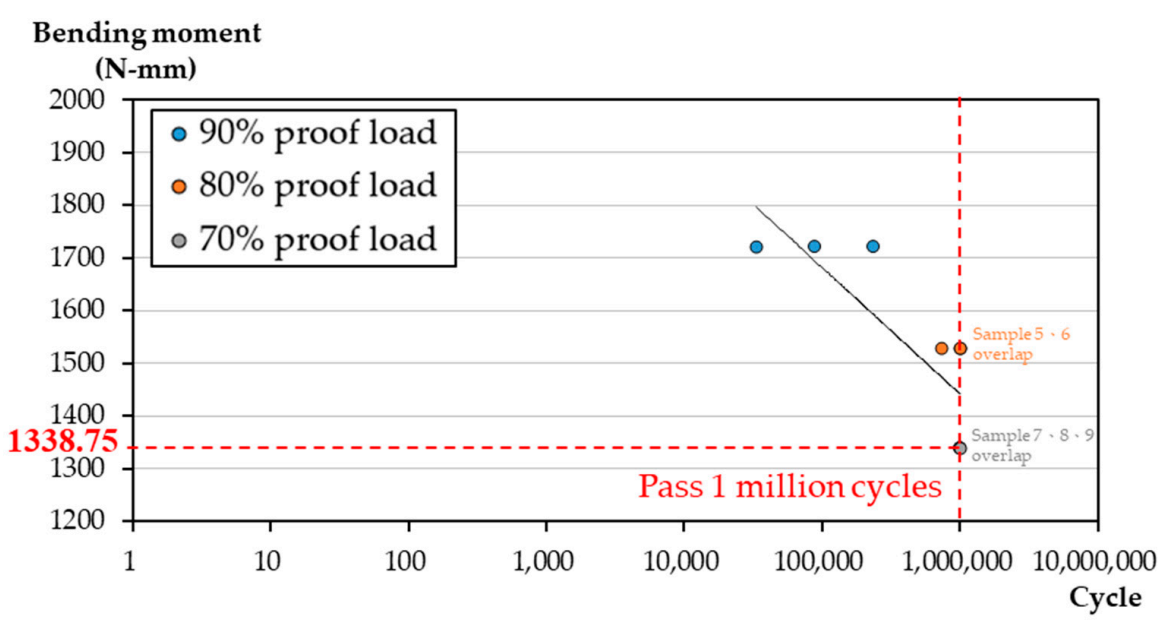

(a)

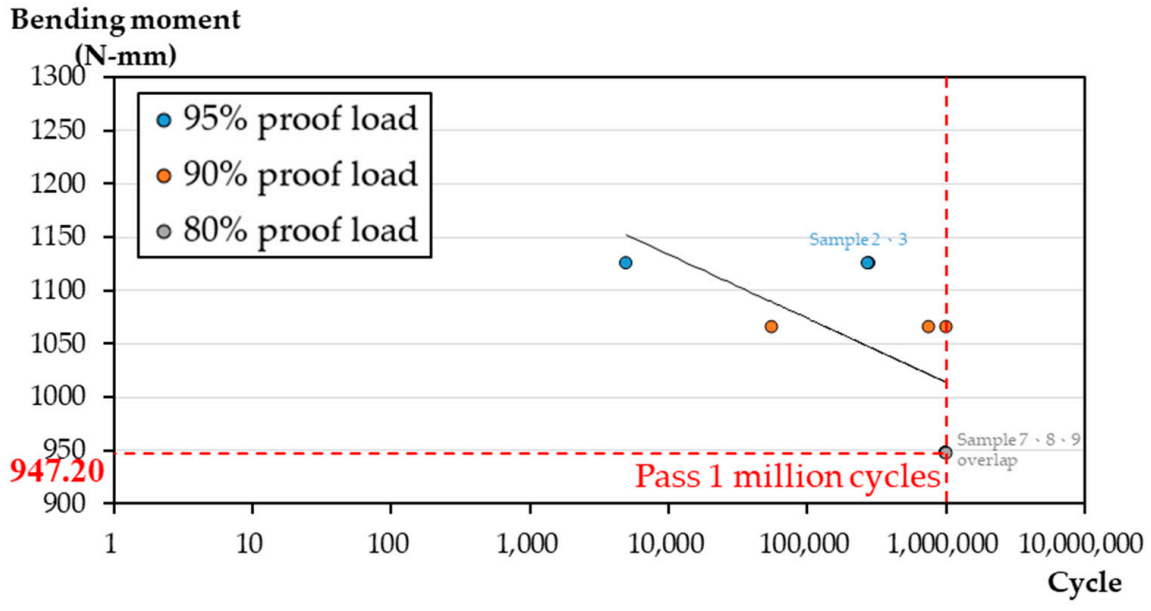

(b)

Figure 5. The four-point bending fatigue test M-N diagrams for HDDP and DDP and their corresponding endurance limit (a) for HDDP and (b) for DDP, i.e., past one-million cycle load.

The failure patterns in the HDDP and DDP groups were different. Plate cracks were found around the fourth locking screw hole from the proximal site, which is also the most distally locking screw hole for radial shaft fixation for the HDDP group. However, slight plate bending deformations without breaks were found in central areas of the plate for the DDP group (Figure 6). 
Table 1. Fatigue four-point bending test results for HDDP and DDP.

\begin{tabular}{|c|c|c|c|c|c|c|}
\hline & $\%$ of Proof Load & $\begin{array}{c}\text { Load }(\mathrm{N}) \\
\text { (Equal to Torque }(\mathrm{N} / \mathrm{mm}))\end{array}$ & $\begin{array}{l}\text { Sample } \\
\text { Number }\end{array}$ & Cycle & Result & $\begin{array}{c}\text { Temp/Humidity } \\
\left({ }^{\circ} \mathrm{C} / \%\right)\end{array}$ \\
\hline \multirow{9}{*}{ HDDP } & \multirow{3}{*}{$90 \%$} & \multirow{3}{*}{$\begin{array}{c}9.83 \sim 98.30 \\
(172.03 \sim 1720.25)\end{array}$} & 1 & 33,000 & Failure & $22{ }^{\circ} \mathrm{C} / 70 \%$ \\
\hline & & & 2 & 89,000 & Failure & $22{ }^{\circ} \mathrm{C} / 70 \%$ \\
\hline & & & 3 & 237,000 & Failure & $22{ }^{\circ} \mathrm{C} / 70 \%$ \\
\hline & \multirow{3}{*}{$80 \%$} & \multirow{3}{*}{$\begin{array}{c}8.74 \sim 87.40 \\
(152.95 \sim 1529.5)\end{array}$} & 4 & 729,000 & Failure & $22{ }^{\circ} \mathrm{C} / 70 \%$ \\
\hline & & & 5 & $1,000,000$ & Pass & $22{ }^{\circ} \mathrm{C} / 70 \%$ \\
\hline & & & 6 & $1,000,000$ & Pass & $22{ }^{\circ} \mathrm{C} / 70 \%$ \\
\hline & \multirow{3}{*}{$70 \%$} & \multirow{3}{*}{$\begin{array}{c}7.65 \sim 76.50 \\
(133.88 \sim 1338.75)\end{array}$} & 7 & $1,000,000$ & Pass & $22{ }^{\circ} \mathrm{C} / 70 \%$ \\
\hline & & & 8 & $1,000,000$ & Pass & $22{ }^{\circ} \mathrm{C} / 70 \%$ \\
\hline & & & 9 & $1,000,000$ & Pass & $22{ }^{\circ} \mathrm{C} / 70 \%$ \\
\hline \multirow{9}{*}{$\begin{array}{l}\text { Synthes Dorsal } \\
\text { Plate }\end{array}$} & \multirow{3}{*}{$95 \%$} & \multirow{3}{*}{$4.50 \sim 45.00(112.50 \sim 1125.00)$} & 1 & 5000 & Failure & $22{ }^{\circ} \mathrm{C} / 70 \%$ \\
\hline & & & 2 & 281,921 & Failure & $22{ }^{\circ} \mathrm{C} / 70 \%$ \\
\hline & & & 3 & 272,272 & Failure & $22{ }^{\circ} \mathrm{C} / 70 \%$ \\
\hline & \multirow{3}{*}{$90 \%$} & \multirow{3}{*}{$2.26 \sim 42.62$ (106.56 1065.60) } & 4 & 54,998 & Failure & $22{ }^{\circ} \mathrm{C} / 70 \%$ \\
\hline & & & 5 & $1,000,000$ & Pass & $22{ }^{\circ} \mathrm{C} / 70 \%$ \\
\hline & & & 6 & 739,758 & Failure & $22{ }^{\circ} \mathrm{C} / 70 \%$ \\
\hline & \multirow{3}{*}{$80 \%$} & \multirow{3}{*}{$2.49 \sim 37.89$ (94.72 947.20) } & 7 & $1,000,000$ & Pass & $22{ }^{\circ} \mathrm{C} / 70 \%$ \\
\hline & & & 8 & $1,000,000$ & Pass & $22{ }^{\circ} \mathrm{C} / 70 \%$ \\
\hline & & & 9 & $1,000,000$ & Pass & $22{ }^{\circ} \mathrm{C} / 70 \%$ \\
\hline
\end{tabular}
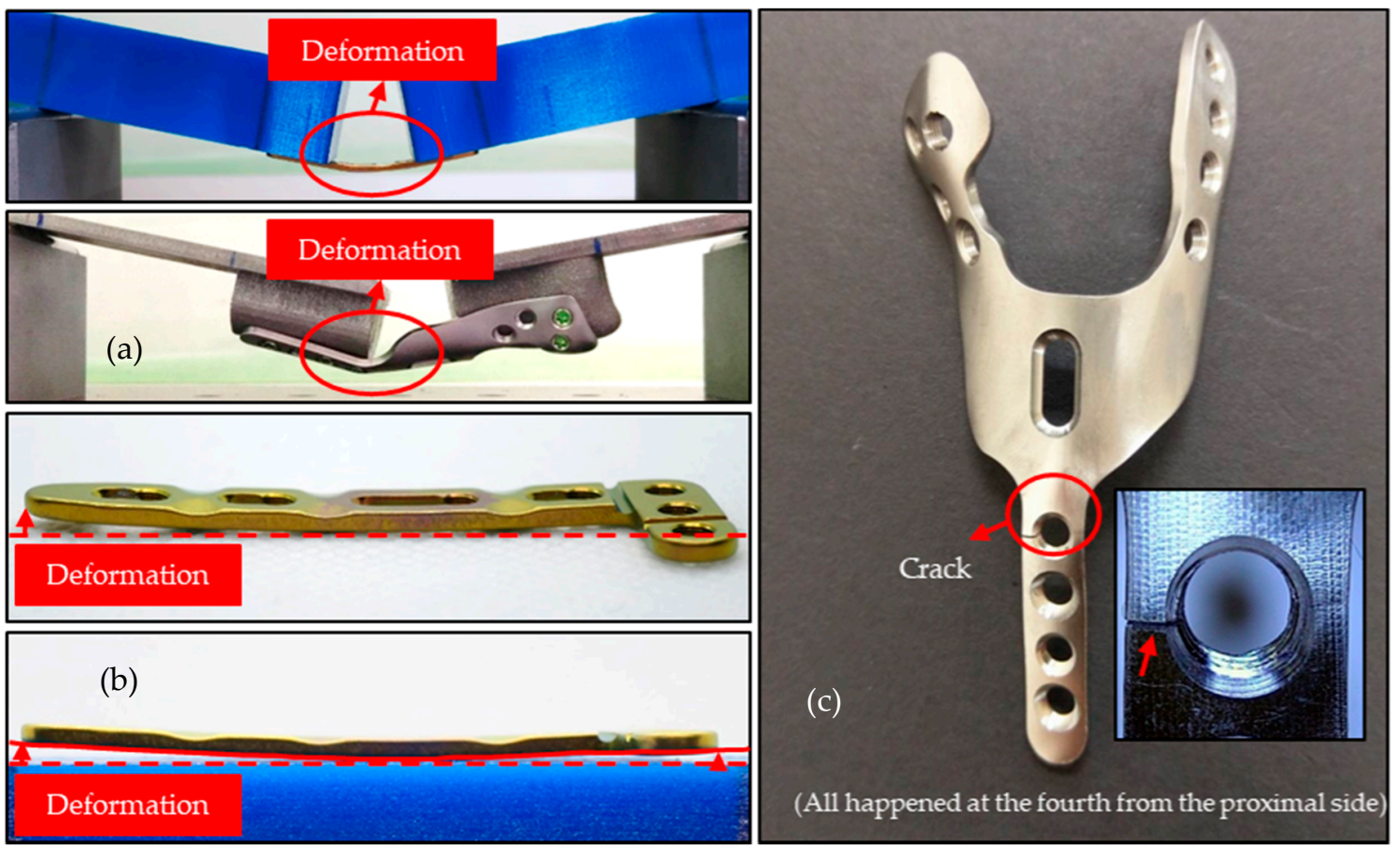

Figure 6. HDDP and DDP group case failure patterns. Deformations of (a) HDDP; (b) DDP and (c) cracks of HDDP.

The biomechanical fatigue test result showed that average axial displacement values under axial load for the HDDP and DDP groups were $0.4218 \mathrm{~mm}$ and $0.5162 \mathrm{~mm}$, respectively. Corresponding HDDP and DDP group values for lateral displacement under bending were $1.7623 \mathrm{~mm}$ and $2.2045 \mathrm{~mm}$; rotational degrees under torsion were $1.9625^{\circ}$ and $1.9736^{\circ}$, respectively (Figure 7). All variations of obtained values under axial load, bending, and torsion showed no significant differences between the HDDP and DDP groups (Table 2). 


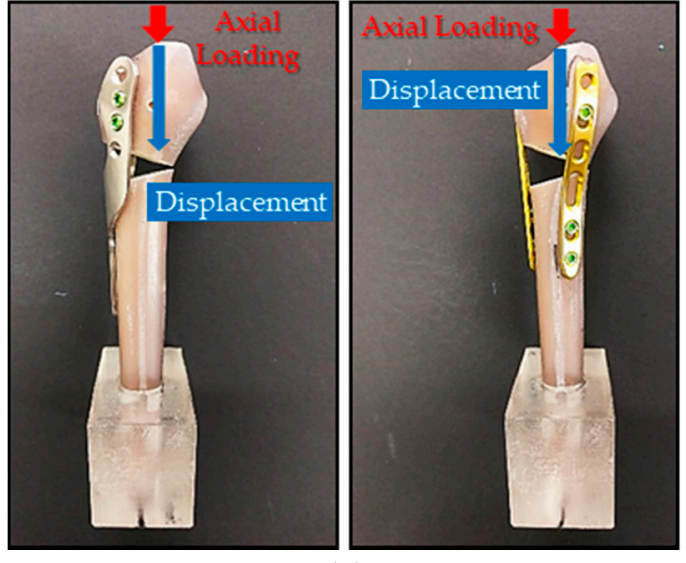

(a)

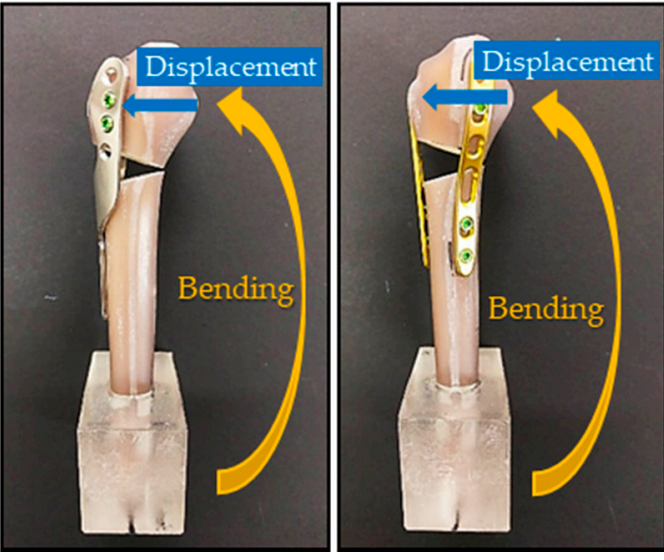

(b)

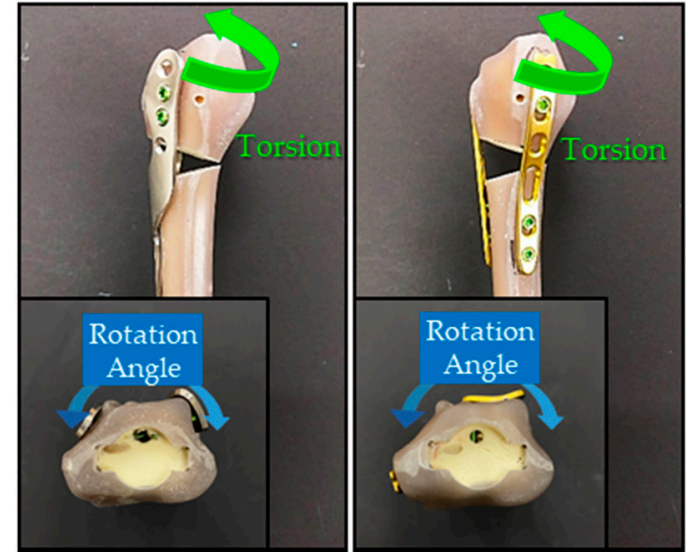

(c)

Figure 7. Illustration of the biomechanical fatigue test displacements under (a) axial load, (b) bending, and (c) torsion.

Table 2. Biomechanical fatigue test displacement results under axial load, bending, and torsion.

\begin{tabular}{|c|c|c|c|c|c|c|}
\hline & \multicolumn{2}{|c|}{$\begin{array}{c}\text { Axial Loading } \\
\text { Maximum Axial Displacement (mm) }\end{array}$} & \multicolumn{2}{|c|}{$\begin{array}{c}\text { Bending } \\
\text { Maximum Bending Displacement (mm) }\end{array}$} & \multicolumn{2}{|c|}{$\begin{array}{c}\text { Torsion } \\
\text { Maximum Angular Displacement (Degree) }\end{array}$} \\
\hline & HDDP & DDP & HDDP & DDP & HDDP & DDP \\
\hline Sample 1 & 0.3797 & 0.8941 & 1.8203 & 1.4245 & 2.3499 & 2.7659 \\
\hline Sample 2 & 0.3818 & 0.3076 & 1.8911 & 3.2378 & 1.3718 & 1.5019 \\
\hline Sample 3 & 0.5039 & 0.3471 & 1.5754 & 1.4113 & 2.1659 & 1.2032 \\
\hline Average Value (Standard deviation) & $\begin{array}{c}0.4218 \\
(0.0581)\end{array}$ & $\begin{array}{c}0.5162 \\
(0.2676)\end{array}$ & $\begin{array}{c}1.7623 \\
(0.1353)\end{array}$ & $\begin{array}{c}2.0245 \\
(0.8579)\end{array}$ & $\begin{array}{c}1.9625 \\
(0.4244)\end{array}$ & $\begin{array}{c}1.8237 \\
(0.6774)\end{array}$ \\
\hline$t$-test $(\alpha=0.05)$ & \multicolumn{2}{|c|}{$\begin{array}{c}p \text {-value }=0.3370>0.05 \\
\text { no significant difference }\end{array}$} & \multicolumn{2}{|c|}{$\begin{array}{c}p \text {-value }=0.3555>0.05 \\
\text { no significant difference }\end{array}$} & \multicolumn{2}{|c|}{$\begin{array}{l}p \text {-value }=0.4109>0.05 \\
\text { no significant difference }\end{array}$} \\
\hline
\end{tabular}




\section{Discussion}

A distal radius fracture is a common fracture. The treatment goals are anatomical reduction, stable fixation, and early mobilization. Obtaining and maintaining an anatomical reduction would lead to a good clinical outcome. For this reason, open reduction and internal fixation have become the most common treatments for these injuries. Good outcomes have been reported with dorsal plates that can buttress the dorsal cortex comminution and maintain distal fragment dorsal displacement reduction $[7,9,14]$. It can be technically demanding to place certain plates on the dorsal surface of the distal radius because of the irregularity. In addition, there is limited soft tissue between the skin and bone surface, which may result in symptomatic fixation plate prominence. Sometimes, extensor tendon irritation or rupture occur due to the tendon making direct contact with a prominent dorsal plate or screws [15-17]. In order to avoid these complications, it is suggested that dorsal plates be low profile. As the indications for operative treatment of displaced distal radius fractures increase, a solid and reliable implant is indispensable. Repetitive axial, bending, and torsion forces accumulated within a distal radius plate over time may lead to plate failure if bone healing is delayed [18]. For this reason, it is important to know the biomechanical characteristics of the available plates.

A novel HDDP is therefore proposed with a " $Y$ "-shaped plate and two ears on the top of the dorsal-radial and -ulnar sides to provide adequate support to the distal fragment. Multiple screws are inserted at the top dorsal-radial/-ulnar ears of the HDDP to enhance stability for treating comminuted or osteoporotic fractures. Additionally, minimally invasive techniques for plate osteosynthesis can be applied with the HDDP due to its advantages in minimizing soft-tissue damage and in preserving the blood supply to the fracture site. The pre-shaped anatomical design of the plate does not require implant adaptation to bone geometry. Due to the low-profile plate design, it is possible to insert it through a small incision. However, in vitro biomechanical experiments need to be performed to verify the mechanical feasibility of the HDDP to supplement the previous results from FE analysis. In order to meet the FDA's requirements for bone plate functional testing and the feasibility of future clinical use, four-point bending mechanical testing and fatigue biomechanical testing were planned under physiological load conditions.

Four-point bending testing is a specification and test method that provides a comprehensive reference for bone plates used in skeletal system surgical internal fixation. The standard establishes consistent methods to classify and define the geometric characteristics and performance characteristics of bone plates. It is not the intention of the standard to define levels of performance or case-specific clinical performance for bone plates, as insufficient knowledge is available to predict the consequences from their use in individual patients for specific activities of daily living [19]. The static test result showed that the proof load, bending strength, and bending stiffness of the HDDPs were all significantly higher than those of DDPs. This might be due to the fact that the material yield strength of HDDP (titanium alloy) and the second moment of inertia of the relative plate cross-sectional area were higher than that of DDP (pure titanium). In the fatigue endurance limit comparison, the bending strength values were compared between HDDP and DDPs, instead of proof load, because of the HDDP complex geometry rather than the DPP flat plate. Obviously, the HDDP endurance limit $(1338.75 \mathrm{~N} / \mathrm{mm})$ was higher than that of DDP $(947.20 \mathrm{~N} / \mathrm{mm})$. This result shows that substantial functional test equivalence between HDDP and DDP under the same clinical indication can meet FDA requirements for a safe and effective legally marketed device. Moreover, the majority of the failures in HDDP were plate-screw interface failure, whereas DDP displayed more plate deformation. The failure mechanisms determined here at least partially explain the clinically observed plate failure problem. The Synthes dorsal plates showed signs of plastic deformation already at loads below $50 \mathrm{~N}$ in the single static test. It is conceivable that everyday situations might lead to plate dorsal and volar bending, which might lead to plate failure in the long run. A study pointed out that loads transmitted to the distal radius are about $50 \mathrm{~N}$ for each $10 \mathrm{~N}$ of grip forces [12]. 
However, the HDDP was relatively safe because its proof load was nearly twice that of Synthes dorsal plates.

Fatigue biomechanical testing using artificial Sawbone under physiological loads was performed to understand the mechanical behaviors for HDDP and commercial plates. This is because the loads close to the fracture area are always changing and repeating when active finger mobilizations are performed during the acute healing period. Cyclic loading rather than single loading was included in these experiments. Artificial Sawbone was used because the size and shape are easier to standardize, making the mechanical evaluation and comparison more reliable. As suggested in a previous publication, we tested for torsional and axial compression as well as bending [13]. The loads used in this study were designed to be comparable with the loads applied to the distal radius during early postoperative hand and wrist mobilization. Loads transmitted to the distal radius were about $50 \mathrm{~N}$ for each $10 \mathrm{~N}$ of grip forces with various hand positions and radius lengths [12]. Although the compression forces on the distal radius in vivo have not yet been clearly defined, several studies suggested that compressive forces created by light, active wrist motion do not exceed $100 \mathrm{~N}$. Combined wrist and digit forces of motion do not exceed more than $250 \mathrm{~N}$ [10,20-22]. Therefore, in our study, the specimens were performed under load control to a force of $150 \mathrm{~N}$ for axial compression, $55 \mathrm{~N}$ for bending (about 11,000 N/mm bending moment), and 10,000 N/mm for torsion.

However, our results showed that there were no significant differences for maximum axial, bending, and torsional displacements between the HDDP and commercial DDP constructs. This result indicates that the HDDP dorsal plate biomechanical performance was as safe as the commercial DDP product. However, further observation showed that the average HDDP displacements in axial and bending were smaller than those for the commercial DDP, while the relative torsional value was higher. This result implied that HDDP use should try to avoid forearm pronation and supination after surgery. In general, the novel HDDP should be able to further undergo clinical trials based on biomechanical testing results, less surgical time, and smaller surgical wound.

There were limitations in this study, including one simple fracture (2R3A3.1) model and independent physical loads that do not interfere with each other being only considered in our biomechanical fatigue testing. More complex fractures and cadaver samples may be taken into account in further in vitro testing to assess the safety and effectiveness of the HDDP in treating selected distal radius fractures. Furthermore, this study focused on the macroscopic stability comparison of fixations but lacked the microcosmic strain analysis of fragment interfaces. In considering healing objectives, a continuous principal strain analysis comparison study can be executed in the future.

\section{Conclusions}

This study showed the mechanical superiority of the HDDP compared with a regular straight dorsal plate in a four-point bending test. The fatigue biomechanical testing result under axial load, bending, and torsion displayed no significant difference for corresponding displacements between the HDDP and commercial DDP constructs in extra-articular distal radius fractures. However, everyday movements are complex and bone-plate construct stability in multiple directions can contribute to fixation failure. Thus, further clinical studies are required to investigate the implications of HDDP. The current investigation was the first to biomechanically compare HDDP fixation with dorsal double plating of distal radius fractures, providing a quantitative assessment of an alternative fixation strategy. We recommend the HDDP for clinical use, especially when treating comminuted or osteoporotic fractures based on our biomechanical results and in agreement with our clinical experience.

Author Contributions: All authors have made substantial contributions to the conception and design of this study. H.-C.L. and Y.-H.Z. were involved in data collection and data analysis. H.-C.L., C.-L.L. and Y.-H.Z. were involved in data interpretation, drafting the manuscript, and revising the manuscript critically and gave final approval of the version to be published. All authors have read and agreed to the published version of the manuscript. 
Funding: This study is supported in part by the MOST project 108-2622-E-010-001-CC2 and 108-2622B-010-005, Taiwan.

Institutional Review Board Statement: Not applicable.

Informed Consent Statement: Not applicable.

Data Availability Statement: Not applicable.

Conflicts of Interest: The authors declare no conflict of interest.

\section{References}

1. Court-Brown, C.M.; Caesar, B. Epidemiology of adult fractures: A review. Int. J. Care Inj. 2016, 37, 691-697. [CrossRef]

2. Kevin, L.; Boyer, M.; Goldfarb, C. Dorsal locked plate fixation of distal radius fractures. J. Hand Surg. 2013, 38, 414-1422.

3. Rikli, D.A.; Regazzoni, P. The double plating technique for distal radius fractures. Tech. Hand Up. Extrem. Surg. 2000, 4, 107-114. [CrossRef] [PubMed]

4. Lin, Y.H.; Chen, A.; Kuo, H.N.; Yu, T.C.; Sun, M.T.; Lin, C.L. Biomechanical evaluation of a modified dorsal double-plating fixation with adjustable joint and microthread designs for comminuted extra-articular distal radius fractures. J. Med. Biol. Eng. 2013, 33, 29-34. [CrossRef]

5. Liu, H.C.; Jiang, J.S.; Lin, C.L. Biomechanical investigation of a novel hybrid dorsal double plating for distal radius fractures by integrating topology optimization and finite element analysis. Injury 2020, 51, 1271-1280. [CrossRef]

6. Reed, J.D.; Stanbury, S.J.; Menorca, R.M.; Elfar, J.C. The emerging utility of composite bone models in biomechanical studies of the hand and upper extremity. J. Hand Surg. Am. 2013, 38, 583-587. [CrossRef]

7. Chen, A.; Lin, Y.H.; Kuo, H.N.; Yu, T.C.; Sun, M.T.; Lin, C.L. Design optimisation and experimental evaluation of dorsal double plating fixation for distal radius fracture. Int. J. Care Inj. 2013, 44, 527-534. [CrossRef] [PubMed]

8. Schorler, H.; Wendlandt, R.; Jürgens, C.; Schulz, A.P.; Kaddick, C.; Capanni, F. Bone plate-screw constructs for osteosynthesisRecommendations for standardized mechanical torsion and bending tests. Biomed. Tech. 2018, 63, 719-727. [CrossRef]

9. Lin, C.L.; Lin, Y.H.; Chen, A. Buttressing angle of the double-plating fixation of a distal radius fracture: A finite element study. Med. Bio. Eng. Comput. 2006, 44, 665-673. [CrossRef] [PubMed]

10. Chao, E.Y.; Opgrande, J.D.; Axmear, F.E. Three-dimensional force analysis of finger joints in selected isometric hand functions. J. Biomech. 1976, 9, 387-396. [CrossRef]

11. Lill, H.; Hepp, P.; Korne, J.; Kassi, J.P.; Verheyden, A.P.; Josten, C.; Duda, G.N. Proximal humeral fractures: How stiff should an implant be? A comparative mechanical study with new implants in human specimens. Arch. Orthop. Trauma Surg. 2003, 123, 74-81. [CrossRef]

12. Putnam, M.D.; Meyer, N.J.; Nelson, E.W.; Gesensway, D.; Lewis, J.L. Distal radial metaphyseal forces in an extrinsic grip model: Implications for post fracture rehabilitation. J. Hand Surg. Am. 2000, 25, 469-475. [CrossRef]

13. Caiti, G.; Dobbe, J.G.G.; Bervoets, E.; Beerens, M.; Strackee, S.D.; Strijker, G.J.; Streekstra, G.J. Biomechanical considerations in the design of patient-specific fixation plates for the distal radius. Med. Biol. Eng. Comput. 2019, 57, 1099-1107. [CrossRef] [PubMed]

14. Cheng, H.Y.K.; Lin, C.L.; Lin, Y.H.; Chen, A. Biomechanical evaluation of the modified double-plating fixation for the distal radius fracture. Clin. Biomech. 2007, 22, 510-517. [CrossRef] [PubMed]

15. Trease, C.; McIff, T.; Toby, E.B. Locking versus nonlocking T-plates for dorsal and volar fixation of dorsally comminuted distal radius fractures: A biomechanical study. J. Hand Surg. Am. 2005, 30, 756-763. [CrossRef]

16. Ruch, D.S.; Papadonikolakis, A. Volar versus dorsal plating in the management of intra-articular distal radius fractures. J. Hand Surg. Am. 2006, 31, 9-16. [CrossRef] [PubMed]

17. Gondusky, J.S.; Carney, J.; Erpenbach, J.; Robertson, C.; Mahar, A.; Oka, R.; Thompson, M.; Mazurek, M. Biomechanical comparison of locking versus nonlocking volar and dorsal T-plates for fixation of dorsally comminuted distal radius fractures. J. Orthop. Trauma 2011, 25, 44-50. [CrossRef] [PubMed]

18. Cao, J.; Ozer, K. Failure of volar locking plate fixation of an extraarticular distal radius fracture: A case report. Patient Saf. Surg. 2010, 4, 19. [CrossRef]

19. Liu, X.; Wu, W.D.; Fang, Y.F.; Zhang, M.C.; Huang, W.H. Biomechanical comparison of osteoporotic distal radius fractures fixed by distal locking screws with different length. PLOS ONE 2014, 9, e103371. [CrossRef]

20. Cooney, W.P., 3rd; Chao, E.Y.S. Biomechanical analysis of static forces in the thumb during hand function. J. Bone Jt. Surg. Am. 1977, 59, 27-36. [CrossRef]

21. Horii, E.; Garcia-Elias, M.; An, K.N.; Bishop, A.T.; Cooney, W.P.; Linscheid, R.L.; Chao, E.Y.S. Effect on force transmission across the carpus in procedures used to treat Kienbock's disease. J. Hand Surg. Am. 1990, 15, 393-400. [CrossRef]

22. Peine, R.; Rikli, D.A.; Hoffmann, R.; Duda, G.; Regazzoni, P. Comparison of three different plating techniques for the dorsum of the distal radius: A biomechanical study. J. Hand Surg. Am. 2000, 25, 29-33. [CrossRef] [PubMed] 